\title{
VIRTUAL HOME TEST BENCH FOR DOMESTIC ENERGY MANAGEMENT SOLUTIONS
}

\author{
JOHANNES ÜPPING, KIM ALINA FORCHE, NORMAN SCHMIDTMEIER, \\ TOBIAS GRAESKE \& DANIEL SCHRÖDER \\ Institut Future Energy, Hochschule Ostwestfalen-Lippe, Germany
}

\begin{abstract}
One of society's major goals within the next decades will be to make the energy supply fully renewable. Up to now energy management systems still need to be incorporated into industry processes and residential buildings. In this paper, a test bench that evaluates energy management systems using electronic loads and a calculation and controller engine to create characteristic consumption profiles for residential buildings is presented. Within this test bench different situations and installations can be tested and different consumption profiles can be used. The modular test bench can handle simple test cases with pure energy management relying on time-depending energy prices and also complex houses using, for example, an inverter heat pump, photovoltaics and/or a battery storage.

Keywords: energy management, virtual house, prediction, building, energy consumption, engineering methods, HVAC systems.
\end{abstract}

\section{INTRODUCTION}

In recent years, the renewable fraction of electricity generation in Germany and the whole world increased significantly [1], [2]. One of the greatest challenges is to balance the volatility of photovoltaic and wind power production and to correlate energy generation and consumption [3]. Whereas in Mediterranean countries high energy demand coincides with high energy generation, due to a high cooling and a low heating load, the largest load in northern countries accrues in times of low solar yields.

A possible solution is the storage of electric energy in battery systems, where the construction and dimensioning of the storage system is very individual [4]. The electric energy could also be transformed into thermal energy and directed towards thermal storages [5], [6]. Examples are fluid reservoirs or solid matter containers. In most cases a combination of both storage types leads to a good system.

Furthermore, load shifting and energy management offer great potential [7]-[9]. A holistic energy management, with the possibility to shift loads into high-yielding times and load the storage at low-consumption times, helps to increase the self-consumption rate and the self-sufficiency of the systems.

But these systems need a lot of information about the current and prospective energy status of the building. Often additional computers are used for the control of the devices, the connection to the internet, the communication with the residents and the calculations. Testing the systems in the field turns out to be very complex since the weather conditions and the behaviour of the residents cannot be controlled and thus no reproducible test conditions can be achieved. In the development of these systems is therefore often resorted to pure simulations or extensive field tests. However, in pure simulations normally rather Softwarein-the-Loop (SIL) tests are used that do not consider all the physical circumstances. Field tests, on the other hand, can only be evaluated by experts and even then, it is challenging to assess the complex algorithms for diverse buildings with different weather and residents.

In this paper, the concept and the basic implementation of a test bench for energy managements are presented. This test bench establishes the possibility to simulate real 
weather conditions and residents in the form of hardware to provide reproducible testing conditions. That makes it possible to compare systems of different manufacturers and notice fine differences.

The concept of the test bench will at this point be depicted by means of two very simple energy managements using the example of a reference building.

\section{CONCEPT}

Reproducible testing conditions can only be achieved by simulating a building with heating system, consumption and generation units as real as possible. To picture a lot of possibilities a fully electrified reference house will be defined. In complete extension (Fig. 1) the building is equipped with consumption facilities, a photovoltaic production unit, a modulating hot water heat pump and an electric storage system.

All components are connected by the local network (LAN) and electrically attached to the grid via a smart meter. For all billing-relevant information the energy supply company uses the same balance limit as formed by the smart meter. In the test bench system, the photovoltaic unit is illustrated by a Hardware-in-the-Loop (HIL) simulation. This simulation uses corresponding weather conditions and parameters of the photovoltaic system adjusted to the test object. The electrical devices are represented by an adjustable electrical load that allows to imitate three-phase power consumptions with an accuracy of $\Delta P \leq 2 \%$.

When considered in the energy management, the heat pump system will be simulated as a real component with corresponding thermal source and sink conditioning, or also as an electrical load if included as a passive component. Alternatively, a heating system based on fossil energy can be embedded as a simple adjustable electrical load. In addition, the integration of a battery storage is possible.

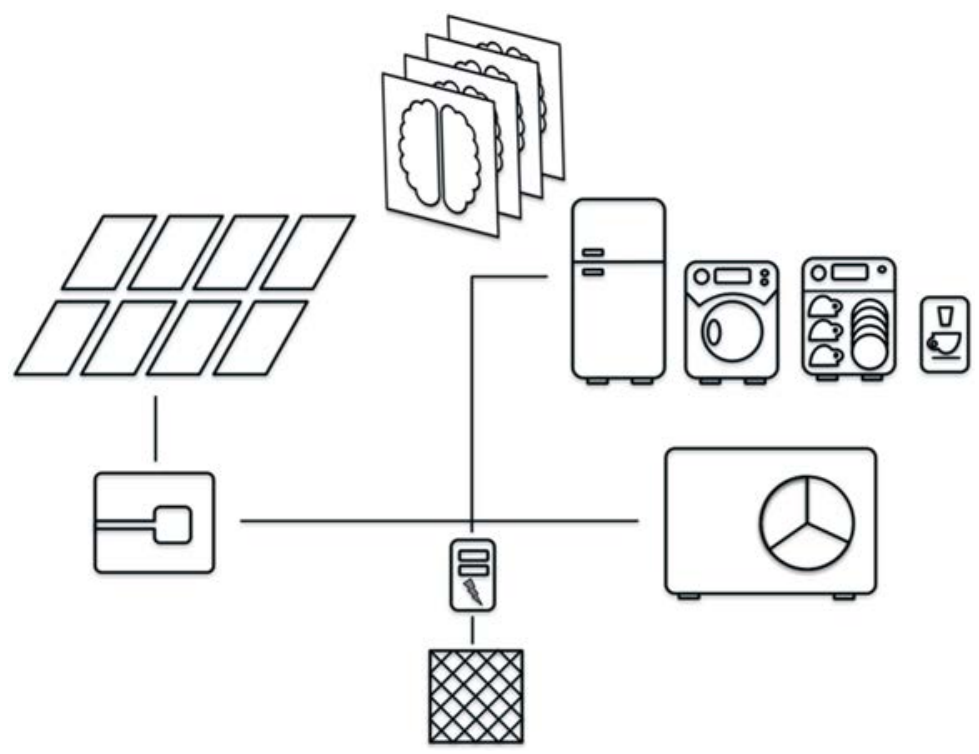

Figure 1: Schematic view of the test bench with a photovoltaic production unit, electrical loads, hot water heat pump and a smart meter. Above the different energy managements are indicated, that can influence the individual subsystems. 


\section{Setup}

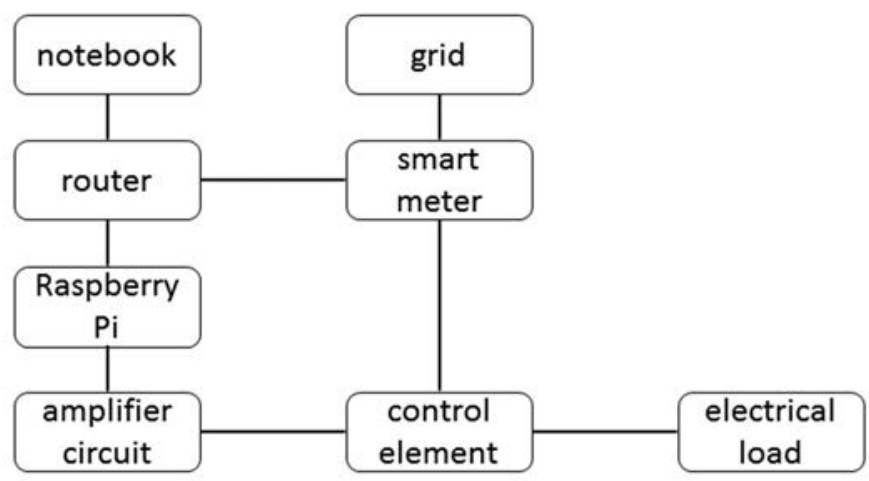

Figure 2: Setup of the test bench.

The setup of the test bench depends on the components considered in the energy management. In this paper, the test scenario includes the load shifting of a dryer, a washing machine and a hot water heat pump. Therefore, the setup is essentially limited to the electrical load that is optimized to the simulation of loads inside a building. The load consists of an amplifier circuit, a router, a smart meter, a control element and an ohmic load (Fig. 2). The ohmic load is represented by a convector since it depicts a pure ohmic load and hence the focus of the measurement is on the active power. The control element is triggered by the amplifier circuit. A fast control loop regulates the used active power to reproduce the consumption profile as exact as possible.

\section{ENERGY MANAGEMENT}

In this paper two different energy managements EM1 and EM2 are considered and compared to the consumption without energy management EM0. The comparison factor will in this case be the financial effort for the consumed energy. Therefore, there have to be temporal differences in the energy price. Here, this will be on the one hand realized by a dual price rate and on the other hand by a price depending on the produced power of the solar system. The total costfunction (Fig. 3) will then be characterized by a mixed price.

In the test scenario considered here, three devices are adjustable by the energy management: a washing machine, a dryer and a hot water heat pump. All three devices have a great shifting potential, as long as the resident supports the energy management actively. Noted should be the difference in the frequency of use. While the washing machine and the dryer are only started once, the hot water heat pump runs at least two times a day. The electrical consumptions of the individual devices are shown in Fig. 4. The consumption of the whole building represents the combined electrical loads without the adjustable devices. 


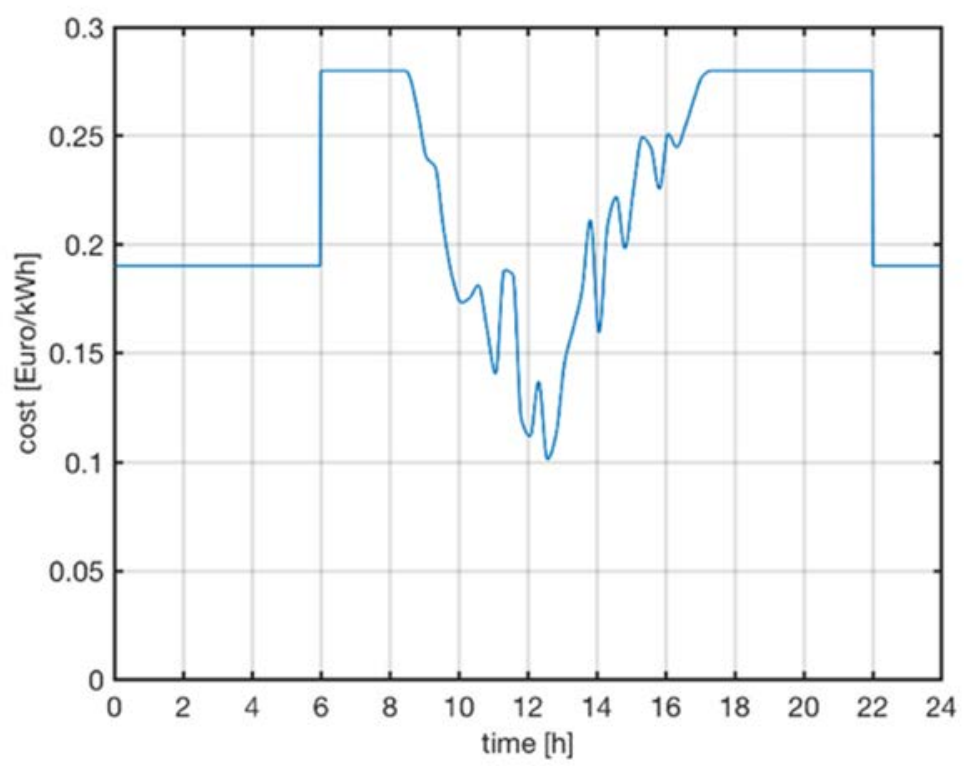

Figure 3: Reference price for electrical energy on the basis of the two energy managements. Observable is the dual price structure at night and the influence of the residential solar system during noon hours.
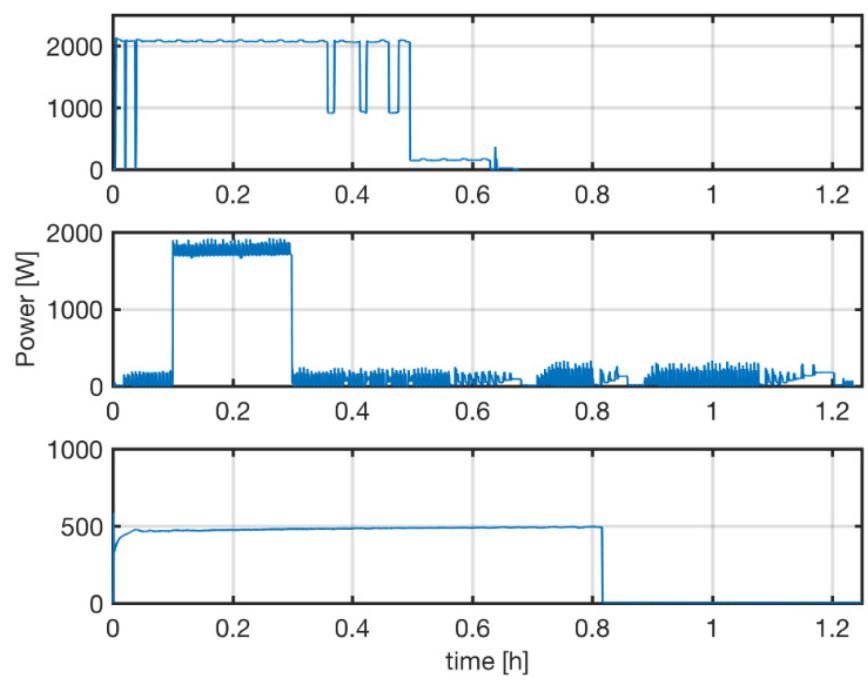

Figure 4: Electrical consumptions of the three adjustable devices. Top: dryer; middle: washing machine; bottom: hot-water heat pump. 


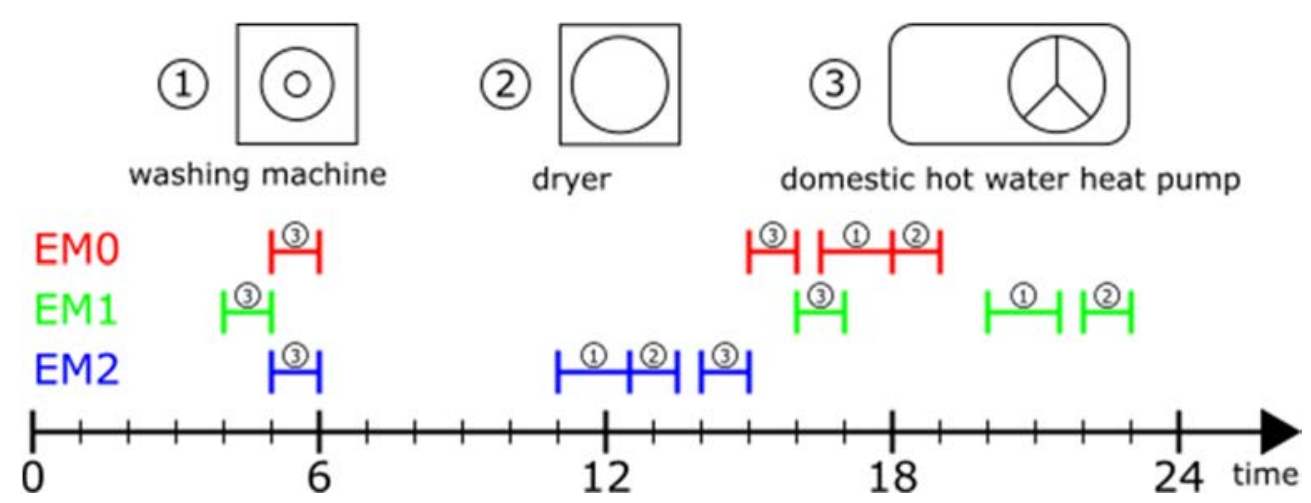

Figure 5: Running times of the adjustable devices according to the three energy managements.

Energy management EM1 only uses the price difference between day and night times ignoring the price reduction due to the solar production. EM1 shifts the loads within the reference day in the low-price phase (night). With this energy management a cost saving of $47 \%$ can be achieved but it will not change the share of electricity from renewable energies. Moreover, like with most energy managements, there is the difficulty of shifting the washing machine and/or the dryer into the low-price phase at night. That demands a lot from the consumers as they have to agree to for example start the washing machine only at $8 \mathrm{pm}$ and the dryer at $10 \mathrm{pm}$. The personal restrictions (work schedule, sleeping hours) do normally not allow to shift both devices into the low-price phase.

EM2, on the other hand, only uses the price difference due to the solar generation and does not take the dual price rate into account. Therefore, the devices should run about noon when the solar yields are highest.

For comparison EM0 is added which represents the case without price-depending energy management. That means that devices are started when it fits best into the time schedule of the consumer. Here, we assumed that the washing machine is started after working hours, directly followed by the dryer. The running times of the three devices according to the three energy managements are shown in Fig. 5.

Of course, these energy managements only serve the purpose of testing the test bench. In a real energy management, reasonably both effects would be considered and a corresponding optimization would be realized.

\section{RESULTS}

The consumption strategies, defined by the energy managements, are simulated and set on the test bench and evaluated with respect to their costs. For EM1, the target powers that have to be simulated (power set) and the actual powers produced by the test bench (power meas.) are shown in Fig. 6a. Since there is a high degree of overlap between both values, nearly no differences are visible. Therefore, an extract of Fig. 6(a) is shown in more detail in Fig. 6(b). 

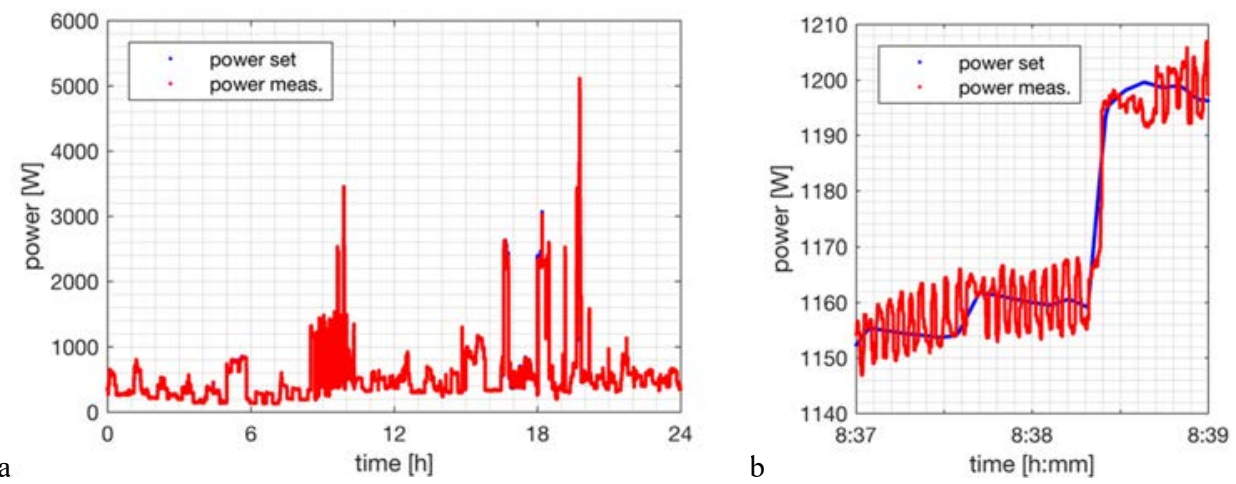

Figure 6: Simulated power (power set) and power load produced by the test bench (power meas.). (a) Complete run of a whole day, where hardly any differences are visible; (b) A two-minute zoom showing the situation in detail.

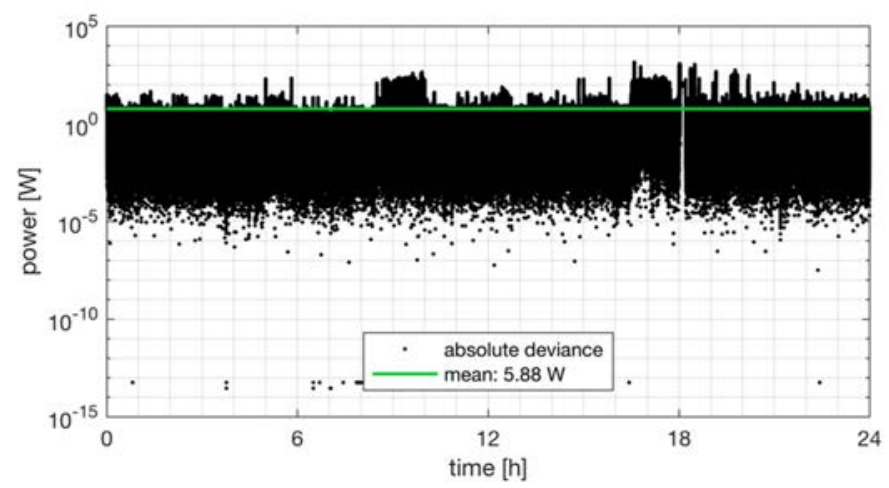

Figure 7: Absolute deviation between power set and power meas. in Watts. The mean value is about $5.88 \mathrm{~W}$.

A calculation of the deviation shows that the test bench replicates the load with an average deviation of $5.88 \mathrm{~W}$, which corresponds to a relative error of $0.98 \%$ (Fig. 7).

The comparison of the total used energy shows a nearly perfect match between the energy set $12.4836 \mathrm{kWh}$ (integration of power set) and the energy meas. $12.4826 \mathrm{kWh}$ (integration of power meas.). In the same way, the simulation and the measurement have also been performed for EM0 and EM2. By means of a cost integration, a ranking list for the considered energy managements is yielded.

Table 1: Comparison of the total energy costs of the reference day.

\begin{tabular}{|l|c|c|c|}
\hline Energy Management & 0 & 1 & 2 \\
\hline $\begin{array}{l}\text { Total cost of energy of the } \\
\text { reference day [Euro] }\end{array}$ & 2.84 & 2.76 & 2.61 \\
\hline
\end{tabular}


In that way, energy managements can be compared with the test bench to support a targeted development.

\section{CONCLUSION}

In the coming years, more and more energy management systems will penetrate the market and an increasing number of smart algorithms will modify the electricity consumption of residential buildings. Testing these systems will be an important pillar in the development of this technology.

In this paper we presented a test bench for energy management sytems and explained the functioning by means of an example. For the further development of the virtual house and the energy management algorithms, the decoupling of the data flows between the test bench and the energy management is important, so that undesired feedbacks can be excluded. In full extension the test bench thus represents a reference environment based on the electrical power supply of a building and serves as an interface between all the energy managements.

A fully-featured virtual house forms the basis for constantly improving and more complex algorithms and is therefore a key requirement for the development of energy management systems.

\section{REFERENCES}

[1] Quaschning, V., Regenerative Energiesysteme, Carl Hanser Verlag GmbH Co KG: München, pp. 18-22, 2015.

[2] Ulrich, A., Development perspectives of the renewable energy sources - the example of Germany and other EU-countries. Journal of Quality and Environmental Studies, 2(1), p. 18, 2016.

[3] Pustka, K., Smart Energy Grids. Network, 57, pp. 57-63, 2012.

[4] Weniger, J., Tjaden, T. \& Quaschning, V., Sizing of residential PV battery systems. Energy Procedia, 46, pp. 78-87, 2014.

[5] Faninger, G., Thermal energy storage. IEA SHC Task, 28, 2004.

[6] Zhang, H., Baeyens, J., Caceres, G., Degreve, J. \& Lv, Y., Thermal energy storage: Recent developments and practical aspects. Progress in Energy and Combustion Science, 53, pp. 1-40, 2016.

[7] Palensky, P \& Dietrich, D., Demand side management: Demand response, intelligent energy systems, and smart loads. IEEE transactions on industrial informatics, 7(3), pp. 381-388, 2011.

[8] Heleno, M., Optimizing PV self-consumption through electric water heater modeling and scheduling, PowerTech, 2015 IEEE Eindhoven, IEEE, pp. 1-6, 2015.

[9] Schellong, W., Analyse und Optimierung von Energieverbundsystemen, SpringerVerlag, pp. 375-517, 2016. 